\title{
Significance of $\alpha$-subunit HCG demonstrated in breast carcinomas by the immunoperoxidase technique
}

\author{
ROSEMARY A. WALKER \\ From the Department of Pathology, Medical School, University of Birmingham B15 2TJ, UK
}

SUMMARY Fifty-three breast carcinomas were examined by an indirect immunoperoxidase technique for the presence of the $\alpha$-subunit of human chorionic gonadotrophin. Positive staining occurred in $12(22.6 \%)$. There was no correlation between $\alpha$-subunit production and specific histological features, but production was related to the presence of lymph node metastases and hence a poorer prognosis. The $\alpha$-subunit could be used as a prognostic indicator in the assessment of breast carcinoma.

The secretion of human chorionic gonadotrophin (HCG) by non-trophoblastic tumours is now well recognised (Weintraub and Rosen, 1971; Braunstein et al., 1973). Braunstein et al. used a radioimmunoassay method to detect HCG in a variety of tumours, of which carcinoma of the breast was one, and there have been similar reports based on the use of an antisera which measured whole molecule HCG and the $\beta$-subunit of HCG (Goldstein et al., 1974). Secretion of the $\alpha$-subunit of HCG, which is very similar in structure to the $\alpha$-subunit of thyroidstimulating hormone (TSH), follicle-stimulating hormone (FSH), and luteinising hormone ( $\mathrm{LH})$, has been described in a small number of carcinomas, including breast (Franchimont et al., 1972), and in HeLa cell lines (Lieblich et al., 1976).

Immunohistochemical methods have given similar results. Using an immunoperoxidase technique Horne et al. (1976) detected HCG in $60 \%$ of breast carcinomas. Naughton et al. (1975) using a similar technique examined human tumour cells, including infiltrating duct breast carcinomas, and detected $\beta$ subunit HCG. Horne et al. found that the patients whose breast carcinomas secreted pregnancy specific proteins (of which HCG is one) had a shorter survival time, and they thought that this could be related to a local immunosuppressive effect by these substances. Naughton et al. also commented that the $\beta$-subunit of HCG could have an immunological role.

Since, therefore, there is good evidence for the production of HCG by breast carcinomas a series

Received for publication 12 September 1977 of such neoplasms was examined retrospectively for the presence of the $\alpha$-subunit of HCG. The morphology of the neoplasms was studied in detail, and in cases in which the lymph nodes had been examined the absence or presence of metastases was noted.

\section{Materials and methods}

Fifty-three carcinomas removed from 52 patients were studied, one patient having bilateral tumours. Out of the 53, 40 were received from the Queen Elizabeth Hospital, Birmingham, between February 1976 and February 1977, and 13 from Selly Oak Hospital, Birmingham, between November 1976 and February 1977. The tissues were fixed in $4 \%$ formaldehyde in $0.15 \mathrm{M}$ sodium chloride solution, dehydrated, cleared, and embedded in paraffin. Sections for morphological examination were stained with haematoxylin and eosin. Specific antiserum was raised in a rabbit against purified $\alpha$-subunit HCG. At $50 \%$ binding the antiserum showed complete cross-reactivity with the a-subunits of TSH, FSH, and $\mathrm{LH} ; 5 \%$ cross-reactivity with $\mathrm{HCG}$, and $<0.3 \%$ with $\beta$-subunit HCG; $11.6 \%$ cross-reactivity with LH and less than $0.3 \%$ with $\beta$-subunit LH; $16 \cdot 3 \%$ cross-reactivity with FSH and $5.2 \%$ with $\beta$-subunit FSH. Cross-reactivity with human growth hormone and human placental lactogen was less than $0.3 \%$.

\section{IMMUNOPEROXIDASE TECHNIQUE}

The method was essentially that described by Curran and Jones (1977). Sections were treated with $0.1 \%$ trypsin (Difco $1: 250$ ) $\mathrm{pH} 7.8$ at $37^{\circ} \mathrm{C}$ for 10,20 , and 30 minutes to 'unmask' the antigen (Curren and 


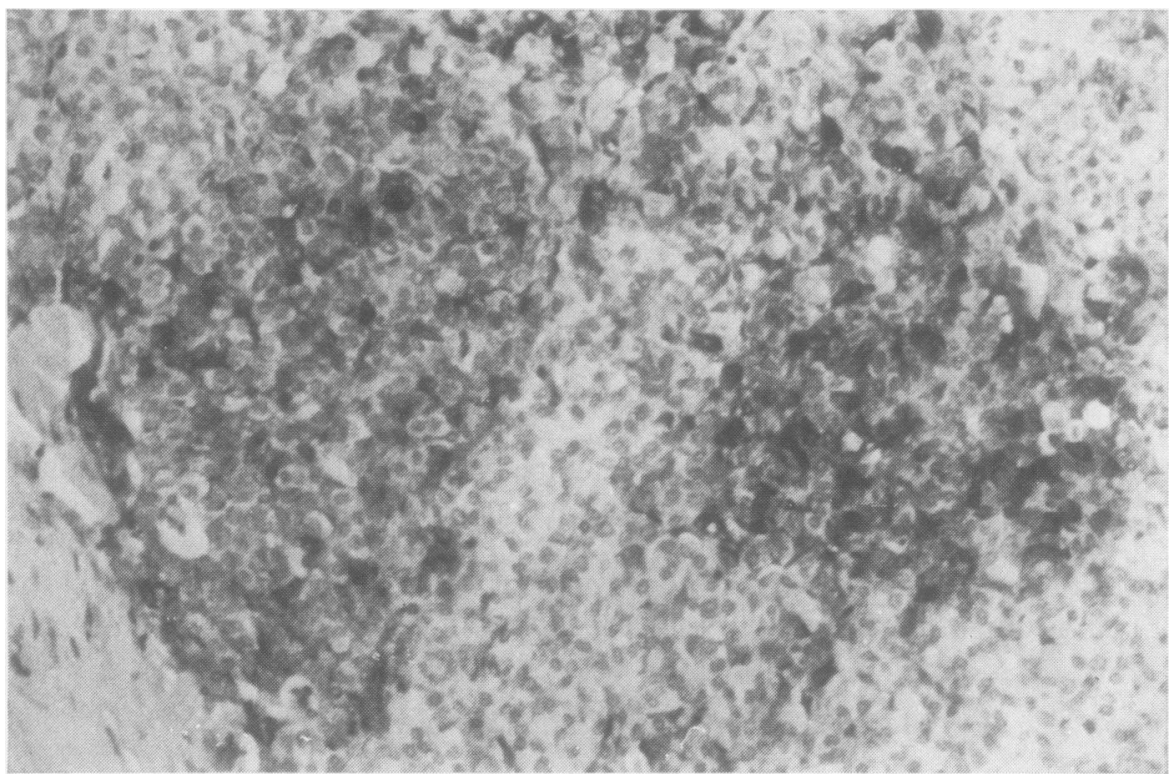

Fig. 1 Part of poorly differentiated breast carcinoma showing clustering of positive cells with negative areas between them. (Immunoperoxidase $\times 140$ )

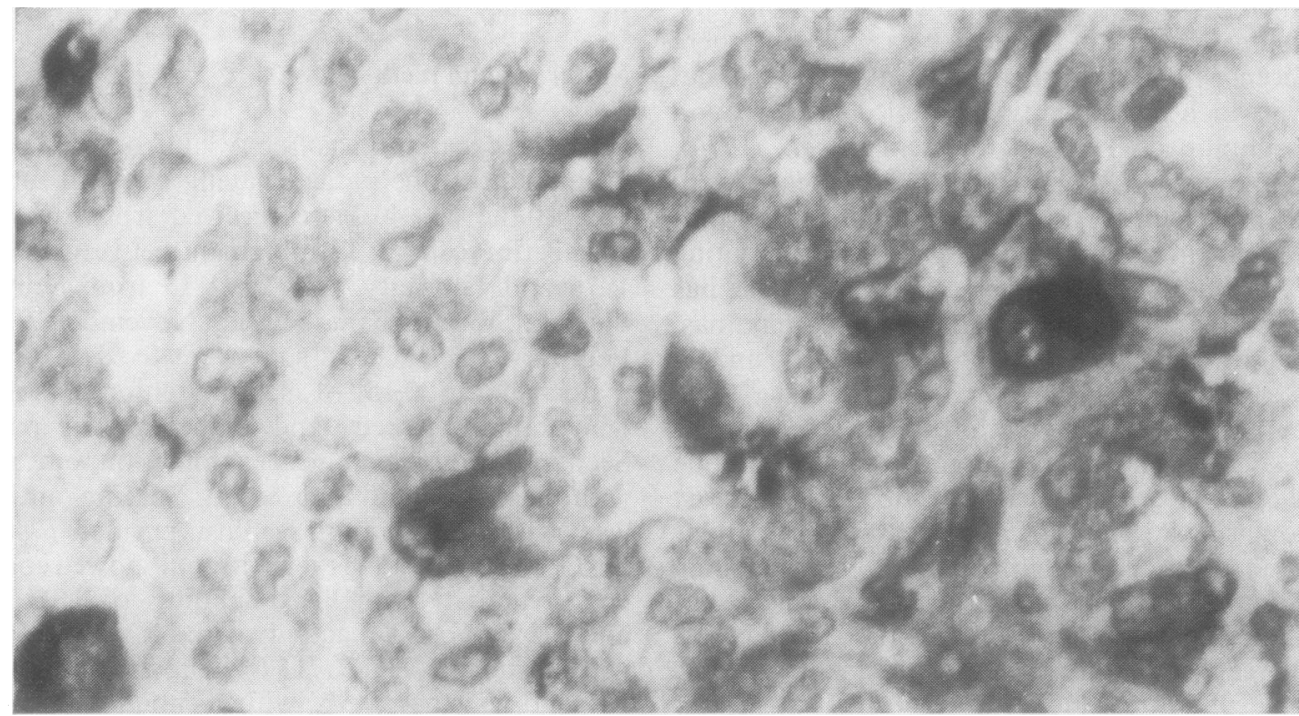

Fig. 2 High-power view of small number of positive cells showing diffuse staining of cytoplasm with focal intenstiy. (Immunoperoxidase $\times 250$ )

Gregory, 1977). Endogenous peroxidase was blocked using $0.2 \% \mathrm{HCl}$ in methanol. Non-specific background staining was reduced by using normal swine serum at a dilution of 1 in 5 for 10 minutes. The sections were then treated with antisera against $a$-subunit HCG. A dilution of 1 in 100 was found to be optimal for staining with negligible backgroun ${ }_{5}$ staining. Swine anti-rabbit gamma-globulin serum (Dakopatt) was then applied, followed by peroxidase $\frac{\text { ? }}{6}$ antiperoxidase complex (Dakopatt). The diamino benzidine reaction was used to localise the site of peroxidase. Control sections were treated witlo 
normal rabbit serum and with specific antiserum after absorption with purified $a$-subunit HCG in place of the specific antiserum. Sections from term placenta which had been processed the same as the carcinomas were treated with specific antiserum.

\section{MORPHOLOGY}

The carcinomas were classified as follows: (1) Noninfiltrative -intraduct, intralobular. (2) Infiltrativeinfiltrating duct, infiltrating lobular, infiltrating (no in-situ seen), medullary, mucinous, and papillary. They were graded according to the criteria of Bloom and Richardson (1957), with 40 random high power fields being examined. The extent of the scirrhous reaction was assessed and graded as absent, mild, moderate, or marked. The lymphocyte infiltration was similarly assessed and divided into two groups depending on whether the infiltrate was throughout the tumour or confined to the periphery. Circumscription of the carcinoma was determined microscopically and noted if present. The absence or presence of metastases in lymph nodes, when these were available, was determined in the same way.

\section{Results}

\section{IMMUNOPEROXIDASE}

Out of the 53 cases $12(22.6 \%)$ gave a positive reaction with the immunoperoxidase technique. In the patient with bilateral carcinomas one was negative and the other positive. There was no staining in control sections treated with normal rabbit serum and none after absorption of the specific antiserum with purified $\alpha$-subunit HCG, $0.67 \mu \mathrm{g}$ being required to absorb a dilution of 1 in 100 . There was staining in the trophoblast of term placenta, a tissue which contains large amounts of $a$-subunit.

The number of cells staining was increased by treatment with trypsin, with the exposure time needed to do this depending on the fixation of the tissue. Each carcinoma varied in the number of cells that stain, but a constant feature was the clustering of positive cells with negative areas of varying sizes between them (Fig. 1). The cytoplasm stained diffusely, with a stronger focal granular reaction predominantly in the perinuclear region (Fig. 2).

\section{MOR PHOLOGY}

The classification and grading of all tumours and positive cases are shown in the Table. All the positive cases were infiltrating duct or infiltrating carcinomas, and their grades correlate with the proportion of grades for all carcinomas. The small number of positive cases made assessment difficult but there was a slight excess of positive cases
Table Classification and grading of all tumours and positive cases

\begin{tabular}{llll}
\hline Classification & $\begin{array}{l}\text { All } \\
\text { carcinomas }\end{array}$ & $\begin{array}{l}\text { Positive } \\
\text { cases }\end{array}$ & $\begin{array}{l}\text { Negative } \\
\text { cases }\end{array}$ \\
\hline $\begin{array}{l}\text { Intraduct carcinoma } \\
\text { Infiltrating duct carcinoma }\end{array}$ & 1 & - & 1 \\
$\begin{array}{l}\text { Infiltrating lobular } \\
\quad \text { carcinoma }\end{array}$ & 4 & 9 & 25 \\
$\begin{array}{l}\text { Infiltrating carcinoma } \\
\text { Medullary carcinoma }\end{array}$ & 11 & - & 4 \\
Mucinous carcinoma & 1 & 3 & 8 \\
Papillary carcinoma & 1 & - & 1 \\
Grade & 1 & - & 1 \\
I & $8(15 \cdot 5 \%)$ & $2(17 \%)$ & $6(25 \%)$ \\
II & $24(46 \%)$ & $5(41 \cdot 5 \%)$ & $19(47.5 \%)$ \\
III & $20(38.5 \%)$ & $5(41.5 \%)$ & $15(37.5 \%)$ \\
\hline
\end{tabular}

(41.6\% (5 out of 12)) showing a marked scirrhous response, compared with $30.0 \%$ (12 out of 40 ) for negative cases. Other categories were comparable. Lymphocytic infiltrate was similar in positive and negative cases.

Overall there were eight carcinomas with microscopic circumscription. Three of them were positive cases. Twenty-two carcinomas had metastases in the lymph node, 22 did not, and in nine cases no lymph nodes were found in the specimen. Eight of the positive cases had metastasised, three had not, and in one case no lymph nodes were found. This showed an excess of metastases when compared with negative cases, in which there were 14 with metastases, 19 without, and eight cases where no lymph nodes were found. If this latter category is included in the node-negative group (although the absence of lymph nodes may be due to the nature of the mastectomy) the excess becomes more striking.

\section{Discussion}

In this study, using the very sensitive indirect immunoperoxidase technique with peroxidaseantiperoxidase complex (Burns, 1975), the $\alpha$-subunit of HCG was detected in 12 out of 53 carcinomas $(22.6 \%)$. Franchimont et al. (1972) found the $a$-subunit in the serum of three patients with breast carcinoma, using a radioimmunoassay method, but did not state the incidence. HCG and $\beta$-subunit HCG have been detected in breast carcinomas by radioimmunoassay methods (Braunstein et al., 1973; Goldstein et al., 1974) and the immunoperoxidase technique (Horne et al., 1976; Naughton et al., 1975), with incidences respectively of $12 \%$, $54 \%$, and $60 \%$. Naughton et al. do not quote incidence. None of these workers mention the $a$-subunit of HCG, which has to be present for the formation of whole molecule HCG.

The pattern of staining is interesting, with 
clustering of positive cells and variable areas of negative cells, suggesting that a clone of cells at the positive site had become derepressed. The finding of diffuse cytoplasmic staining with focal intensity in the perinuclear region differs from the findings for $\beta$-subunit HCG. Naughton et al. (1975) found, using the immunoperoxidase technique on breast carcinoma cells, that there was a more intense band of staining at or near the surface.

Because the production of $a$-subunit might be related to cellular dedifferentiation (Franchimont et al., 1972) the carcinomas were examined histologically to assess differentiation, but there were no differences in grades between those producing $a$-subunit and those not. Although there were slight differences between positive and negative cases in the extent of scirrhous reaction these were not significant. There was no difference in circumscription.

There was, however, an excess of lymph node metastases in those carcinomas producing $a$-subunit. Since the presence of lymph node metastases at the time of presentation is linked with a poorer prognosis these findings tend to support the conclusion of Horne et al. (1976). HCG is said to have immunosuppressive properties (Contractor and Davies, 1973). Positive responses to $a$-subunit HCG as well as HCG and $\beta$-subunit HCG were found by lymphocytes from patients with breast carcinoma, using a macrophage electrophoretic mobility test (Wass et al., 1977).

This study shows that breast carcinoma may now be included with carcinomas of the lung (Tashjian et al., 1973), stomach and pancreas (Rosen and Weintraub, 1974), and HeLa cells (Lieblich et al., 1976) as a tumour that can produce the $\alpha$-subunit. There is no correlation between production and specific histological features. There is a relationship between production and the presence of lymph node metastasis, and hence poorer prognosis. This may be due to immunological factors related to the properties of the $a$-subunit.

The $a$-subunit of HCG could be used as a prognostic indicator in assessing breast carcinoma, but it is of little use diagnostically owing to its relatively low incidence and its presence in other carcinomas.

I thank Professor R. C. Curran for helpful criticism during the preparation of this manuscript and for photography; Dr McKinnell, of Selly Oak Hospital, for sections; Dr S. Smith, of the Department of Endocrinology, Birmingham Women's Hospital, for the $a$-subunit HCG antiserum; Dr A. Howell, Department of Medicine, Queen Elizabeth Hospital, for helpful discussion; and Miss G. L. Parkinson for secretarial help.

\section{References}

Bloom, H. J. G., and Richardson, W. W. (1957). Histo logical grading and prognosis in breast cancer. Britishe Journal of Cancer, 11, 359-377.

Braunstein, G. D., Vaitukaitis, J. L., Carbone, P. P., and Ross, G. T. (1973). Ectopic production of human chorionic gonadotrophin by neoplasms. Annals of In-m ternal Medicine, 78, 39-45.

Burns, J. (1975). Background staining and sensitivity of $\vec{O}$ the unlabelled antibody-enzyme (PAP) method. Com- $\overrightarrow{-}$ parison with the peroxidase labelled antibody sandwich method using formalin fixed paraffin embeddect: material. Histochemistry, 43, 291-294.

Contractor, S. F., and Davies, H. (1973). Effect of human chorionic somatomammotrophin and human chorionicis gonadotrophin on phytohaemagglutinin-inducedin lymphocyte transformation. Nature New Biology, 243, 284-285.

Curran, R. C., and Gregory, J. (1977). The unmasking of antigens in paraffin sections of tissue by trypsinz Experentia, (in press).

Curran, R. C., and Jones, E. L. (1977). Immunoglobulin $\frac{\widehat{\rho}}{-}$ containing cells in human tonsils as demonstrated by $\vec{A}$ immunohistochemistry. Clinical and Experimentat Immunology, 28, 103-115.

Franchimont, P., Gaspard, U., Reuter, A., and Heynen, G. (1972). Polymorphism of protein and polypeptides hormones. Clinical Endocrinology, 1, 315-336.

Goldstein, D. P., Kosasa, T. S., and Skarim, A. T. (1974) The clinical application of a specific radioimmuno-市 assay for human chorionic gonadotrophin in trophoblastic and nontrophoblastic tumors. Surgery, Gyne $\overrightarrow{0}$ cology and Obstetrics, 138, 747-751.

Horne, C. H. W., Reid, I. N., and Milne, G. D. (1976) Prognostic significance of inappropriate production of pregnancy proteins by breast cancers. Lancet, 2 के 279-282.

Lieblich, J. M., Weintraub, B. D., Rosen, S. W., Chou, J. Y., and Robinson, J. C. (1976). HeLa cells secrete $a$. subunit of glycoprotein tropic hormones. Nature, $\mathbf{2 6 0}$, 530-532.

Naughton, M. A., Merrill, D. A., McManus, L. M.,o Fink, L. M., Berman, E., White, M. J., and MartinezHernandez, A. (1975). Localization of the $\beta$ chain of human chorionic gonadotrophin on human tumor cells and placental cells. Cancer Research, 35, 1887-1890 N

Rosen, S. W., and Weintraub, B. D. (1974). Ectopic production of the isolated $\alpha$ subunit of the glycoprotein hormones. New England Journal of Medicine, $\omega$ 290, 1441-1447.

Tashjian, A. H., Jr., Weintraub, B. D., Barowsky, N. J. Rabson, A. S., and Rosen, S. W. (1973). Subunits of

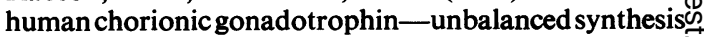
and secretion by clonal cell strains derived from a bronchogenic carcinoma. Proceedings of the Nationato Academy of Science of the United States of America, 70, 1419-1422.

Wass, M., Pentycross, C. R., Rawlins, G. A., and $\mathbb{Q}$ Bagshawe, K. D. (1977). Response of lymphocytes? from cancer patients to human chorionic gonadotrophin. Lancet, 1, 171-172. 
Weintraub, B. D., and Rosen, S. W. (1971). Ectopic production of human chorionic somatomammo- trophin by nontrophoblastic cancers. Journal of Clinical Endocrinology, 32, 94-101.

\section{The February 1978 issue}

\section{THE FEBRUARY 1978 ISSUE CONTAINS THE FOLLOWING PAPERS}

Spectrum of renal tubular damage in renal failure secondary to cirrhosis and fulminant hepatic failure S. P. WILKINSON, D. HIRST, D. W. DAY, AND ROGER WILLIAMS

Hepatocellular carcinoma and hepatic cirrhosis in the west of Scotland: a 25-year necropsy review R. A. BURNETT, R. S. PATRICK, W. G. S. SPILG, W. M. BUCHANAN, AND R. N. M. MACSWEEN

Benign oesophageal papillomatosis W. E. WATERFALL, S. SOMERS, AND D. J. DESA

Squamous carcinoma of the breast P. S. HASLETON, K. A. MISCH, K. S. VASUDEV, AND D. GEORGE

Lymphocyte transformation in cancer patients: variation in results according to technique GILLIAN M. L. GYTE AND SYLVIA M. WATKINS

Crossreaction of antilymphocyte globulin with human granulocyte colony-forming cells A. J. BARRETT, P. LONGHURST, N. ROSENGURT, J. R. HOBBS, AND J. G. HUMBLE

The case for laboratory aides in district clinical chemistry departments DEREK WATSON

International Committee for Standardization in Haematology

Recommendations for reference method for haemoglobinometry in human blood (ICSH Standard EP 6/2: 1977) and specifications for international haemiglobincyanide reference preparation (ICSH Standard EP 6/3: 1977)

Sterilisation in the laboratory autoclave using direct air displacement by steam P. H. EVERALL, C. A. MORRIS, AND R. YARNELL

Sporicidal activity of mixtures of alcohol and hypochlorite D. COATES AND JANET E. DEATH

Effect of bacterial flora on staphylococcal colonisation of the newborn WILLIAM T. SPECK, JOHN M. DRISCOLL, RICHARD A. POLIN, AND HERBERT $S$. ROSENKRANZ
Cerebral ventriculitis associated with Achromobacter xylosoxidans SHIRO SHIGETA, YOSHIO YASUNAGA, KEN HONZUMI, HIROKO OKAMURA, ROKURO KUMATA, AND SHINICHIRO ENDO

Synergy between sulphonamide and trimethoprim in the presence of pus P. N. EDMUNDS

Effect of thymidine on activity of trimethoprim and sulphamethoxazole ANNE STOKES AND R. W. LACEY

Serum standards for the bioassay of aminoglycosides in cerebrospinal fluid S. HAMMERBERG, R. SINAI, AND M. I. MARKS

Routine diagnosis of human rotaviruses in stools G. ZISSIS, J. P. LAMBERT, AND D. De KEGEL

Laboratory diagnosis of EB virus infection in some cases presenting as hepatitis JOAN M. B. EDWARDS, ELISE M. VANDERVELDE, B. J. COHEN, AND D. A. MCSWIGGAN

Isolation of chlamydiae in untreated and Cytochalasin B treated McCoy cells J. J. O'NEILL, BARBARA M. MCLEAN, AND M. H. HAMBLING

Staining clinical specimens for acid-fast bacilli by means of a mechanical conveyor system G. v. HEIMER, NATASHA JOSEPH, AND C. E. D. TAYLOR

Identification of clinical isolates of Neisseria gonorrhoeae by a coagglutination test M. BARNHAM AND A. A. GLYNN

\section{Technical methods}

Anthocyanin BB: a nuclear stain substitute for haematoxylin S. A. AL-TIKRITI AND F. WALKER

Measurement of plasma volume using ${ }^{59} \mathrm{Fe}$-labelled transferrin C. RICKETTS AND I. CAVILL

Letters to the Editor

Book reviews

Copies are still available and may be obtained from the PUBLISHING MANAGER, BRITISH MEDICAL ASSOCIATION, TAVISTOCK SQUARE, LONDON, WC1 H 9JR, price $£ 3.00$, including postage 